Research Article

\title{
Distribution Characteristics and Formation Mechanism of Surface Crack Induced by Extrathick Near Horizontal Seam Mining: An Example from the Datong Coal Field, China
}

\author{
Yueguan Yan $\left(D,{ }^{1}\right.$ Weitao Yan $\left(D,{ }^{2}\right.$ Huayang Dai, ${ }^{1}$ and Junting Guo ${ }^{3}$ \\ ${ }^{1}$ College of Geoscience and Surveying Engineering, China University of Mining and Technology, Beijing 100083, China \\ ${ }^{2}$ School of Surveying and Land Information Engineering, Henan Polytechnic University, Jiaozuo, Henan 454003, China \\ ${ }^{3}$ State Key Laboratory of Groundwater Protection and Utilization by Coal Mining, Beijing 102009, China
}

Correspondence should be addressed to Weitao Yan; yanweitao@hpu.edu.cn

Received 18 February 2021; Revised 7 April 2021; Accepted 21 May 2021; Published 30 May 2021

Academic Editor: Jia Lin

Copyright (C) 2021 Yueguan Yan et al. This is an open access article distributed under the Creative Commons Attribution License, which permits unrestricted use, distribution, and reproduction in any medium, provided the original work is properly cited.

Under the mining condition of extrathick coal seam, the overburden moves violently, the surface is destroyed seriously, and the discontinuous deformation such as cracks is fully developed. Taking Datong mining area as an example, this paper studies and analyzes the development characteristics and generation mechanism of surface cracks in loose layer covered area and bedrock exposed area by means of field measurement and similar model experiment. In the bedrock exposed area, there is no main crack. The width, length, number, and step drop of surface cracks are relatively small. There are many cracks with the same scale and distributed evenly and parallel. However, in the loose covered area, the main cracks are mainly located above the open-off cut and the stoppage line side that is deviated from the working face. There are many secondary cracks around the main crack, with a large crack density and a few cracks in the outer edge of the main crack. Through research, it is found that three mining faces belong to the typical three-zone mining mode and the main fracture is consistent with the O-ring fracture distribution theory. This research's results can provide theoretical and technical support for the follow-up land remediation and ecological restoration.

\section{Introduction}

Coal industry is closely related to sustainable development. From the social, economic, and environmental aspects, it has both positive and negative driving effects $[1,2]$. Coal is a widely distributed energy source in China, mainly concentrated in Xinjiang, Qinghai, Shaanxi, Inner Mongolia, Shanxi, Henan, Hebei, Shandong, Jiangsu, Anhui, and other provinces. The mining of underground coal resources often leads to large-scale overburden movement and surface subsidence. According to the mining subsidence knowledge, the greater the mining thickness, the more serious the surface subsidence. So, when mining the thick seam and extrathick seam, the surface subsidence is the most serious. When the mining thickness of the coal seam is thick or extrathick, the roof is broken seriously. After the mining influence transmits to the ground surface, cracks, collapse pits, landslides, and other disasters are formed. As a result, the buildings in the mining area are seriously damaged, the groundwater level is lowered, the railway and highway are blocked, and the other secondary geological disasters are produced [3-7].

The mining of extrathick coal seam often causes discontinuous damage to the ground surface and then forms the surface cracks $[8,9]$. Up to now, some scholars at home and abroad have studied the distribution law of surface cracks after mining of extrathick coal seam $[10,11]$. Due to the large mining thickness, the failure height of overlying strata can reach $200-350 \mathrm{~m}$ with the mining of extrathick coal seam under the hard roofs [12]. Gao et al. obtained the surface subsidence prediction parameters and angular parameters of Dongpo coal mine and studied the surface subsidence law and its particularity of fully mechanized top coal caving mining in extrathick coal seam under the conditions of near shallow buried depth and medium-thick bedrock [13]. Guo et al. derived the calculation method of surface mining crack width according to the basic 
characteristics of surface movement and surface limit deformation [14]. Gao et al. investigated and analyzed the influence of hard rock crack in different layers on the surface stress distribution under the mining conditions of extrathick coal seam $[15,16]$. Ma et al. used a variety of algorithms to analyze the possibility of landslide caused by thick coal seam mining [17, 18]. Guo et al. discussed the roof support technology under the condition of fully mechanized mining in hard overburden and extrathick coal seam [19]. Lan et al. measured and analyzed the rock movement characteristics of thick coal seam mining under the action of a thick hard roof [20]. Chen et al. analyzed and studied the influence of mining on the underground roadway under the condition of $10 \mathrm{~m}$ mining height and constructed the safety evaluation method [21]. Singh et al. studied the movement mode of overburden under the condition of large mining height in the mountainous area [22]. Huang et al. established the prediction method of residual deformation in the mining of extrathick and steeply inclined coal seam [23]. Wang and Wang studied the movement law and control technology of surrounding rock system under thick coal seam mining [24]. Nayzar et al. analyzed the interaction effects in double extrathick coal seams mining [25]. Matsui et al. studied the underground mining systems for extrathick coal seams [26].

According to the above literature analysis, there are many studies on the surface subsidence law and the distribution characteristics of mining cracks caused by the mining of extrathick steeply inclined coal seams, but there are few studies on the surface mining cracks of extrathick near horizontal coal seams. Therefore, this paper takes a coal mine in Datong City as the research object and uses similar material model experiments to conduct in-depth research on the distribution characteristics and formation mechanism of surface cracks caused by the mining of extrathick near horizontal coal seams.

\section{Survey of Research Area}

2.1. Geological and Mining Conditions of Research Area. The research area is located in a coal mine in Datong City, with a design production capacity of 3 million Ton/year, and the mining face is supported by suspended support. This mine adopts the strike longwall mining method to excavate and the all caving method to manage the roof. The recovery rate is more than $80 \%$. Coal seam 3 is mined in this study area. The buried depth of the coal seam 3 is $295 \sim 380 \mathrm{~m}$, the full thickness is $21.38 \sim 28.01 \mathrm{~m}$, and the dip angle is about $3^{\circ}$. The overlying strata are mostly sandstone and mudstone.

Three longwall working faces are mined, including working faces 1505, 1506, and 1502 successively from south to north. The thickness of the coal seams of the three working faces is $21.20 \sim 32.43 \mathrm{~m}$. The inclination angle of the coal seam is about $3^{\circ}$. In China, when the thickness of the coal seam is more than $3.5 \mathrm{~m}$, it is a thick coal seam, and when the thickness of the coal seam is more than $8.0 \mathrm{~m}$, it is an extrathick coal seam. When the dip angle of the coal seam is less than $8^{\circ}$, it is a near horizontal coal seam. So, these three working surfaces are typical extrathick near horizontal seam mining. The relative position of those working faces is shown in Figure 1.
The mining method of three working faces is fully mechanized top coal caving. The top view and cross-sectional view of the caving situation are shown in Figure 2.

\subsection{Measured Distribution Characteristics of Surface Cracks.} After the three working faces were mined in sequence, various cracks occurred on the surface, as shown in Figure 3.

In Figure 3, the red thick curve represents the large crack with the drop greater than $1 \mathrm{~m}$ and the width greater than $20 \mathrm{~cm}$, also known as the main crack; the blue thin curve represents the crack with the drop less than $1 \mathrm{~m}$ and the width less than $20 \mathrm{~cm}$, referred to as the small crack. It can be seen from Figure 3 that the crack area is located around the goaf, and the crack width and depth in different areas are different. Working face 1502 is close to the mountain, the mountain is steep, and the cracks on the mountain are mainly tensile cracks. The side near the mountain body of working face 1502 is mainly exposed bedrock area, and the north side is the mountain body. The surfaces above the working faces 1505 and 1506 are mainly covered by loess. Compared with the loess area, the shape and distribution of cracks in the bedrock exposed area are different.

\subsubsection{Distribution of Surface Cracks in Loess-Covered Area.} Open-off cut side: In working faces 1505 and 1506, the crack area appears above and outside the open-off cut along the open-off cut direction. The main crack strikes in the northsouth direction and is continuous along this direction. There are two main cracks along the strike direction above the goaf of 1505 working face (Figure 4(a)). The length is $200-220 \mathrm{~m}$. Two main cracks are located at the edge of the goaf, and many small cracks are generated around the main crack about $50 \mathrm{~m}$, which is consistent with the trend of the main crack. The length of small parallel cracks is $50-180 \mathrm{~m}$.

Stop mining line side: The cracks at the stop line of working faces 1505 and 1506 are located on the inner side of the working face, and there are several similar cracks with large lengths and widths. There are many small- and medium-sized cracks at the stop line of working face 1505 near the farmland, which have great density and complexity, and seriously damage the farmland. A large area of stepped arcshaped cracks appeared at the stop line of working face 1506. The depth of the main crack is about $2.4 \mathrm{~m}$. The distribution of the cracks is regular. There are few cracks in the outer edge of several main cracks. The cracks are mainly close to the side of the belt roadway, just above the mining area.

Above the goaf: The middle part of the goaf of working faces 1505 and 1506 showed overall collapse, there are large cracks and many cracks of different sizes (Figure 4(b)). The distribution density of cracks is not uniform, the strike direction is not consistent, and the damage degree is different. Through field survey, the large-scale surface deformation area of this type of goaf occurs within the boundary of working face $130 \mathrm{~m}$. The surface deformation is a typical "cutting and caving form," which shows that the deformation of the upper part of the mining boundary and the surrounding area is strong, and the deformation outside the crack is greatly weakened (Figure $4(\mathrm{c})$ ). 


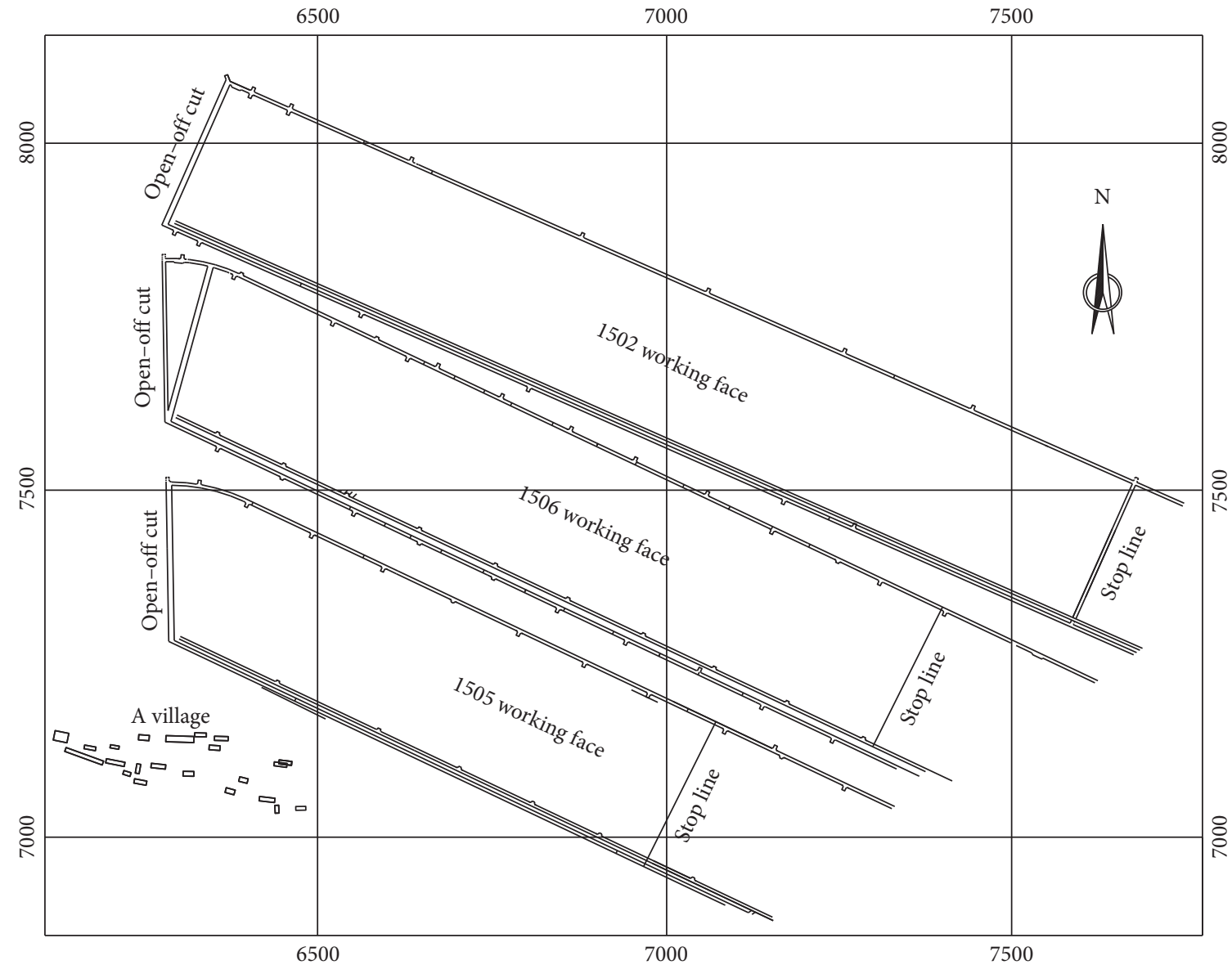

FIgURE 1: Working face layout.

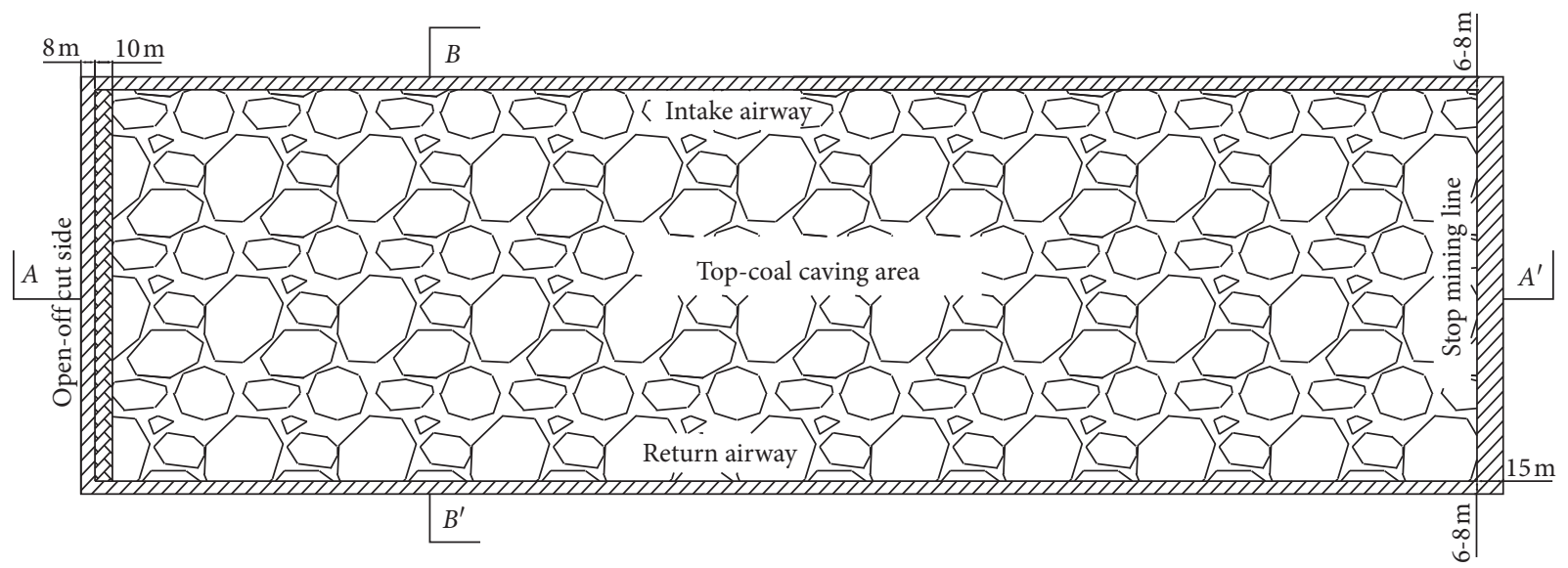

Sop-coal caving area

Incomplete top-coal caving area

QIIT No top-coal caving area

(a)

FIgUre 2: Continued. 


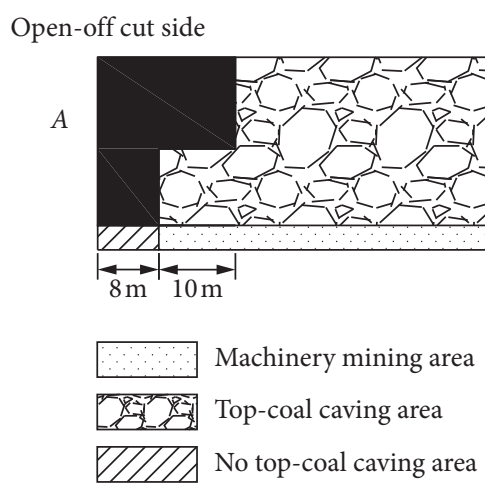

Stop mining line side

(b)

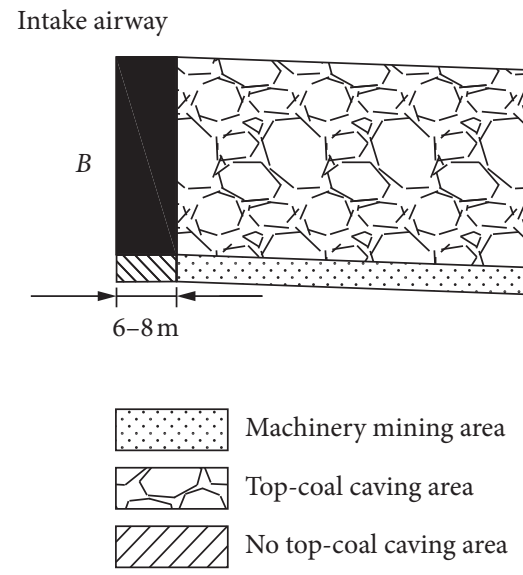

(c)

Figure 2: Top and cross-sectional view of the caving situation. (a) Top view. (b) Cross-sectional view of line $A A^{\prime}$. (c) Cross-sectional view of line $B B^{\prime}$.

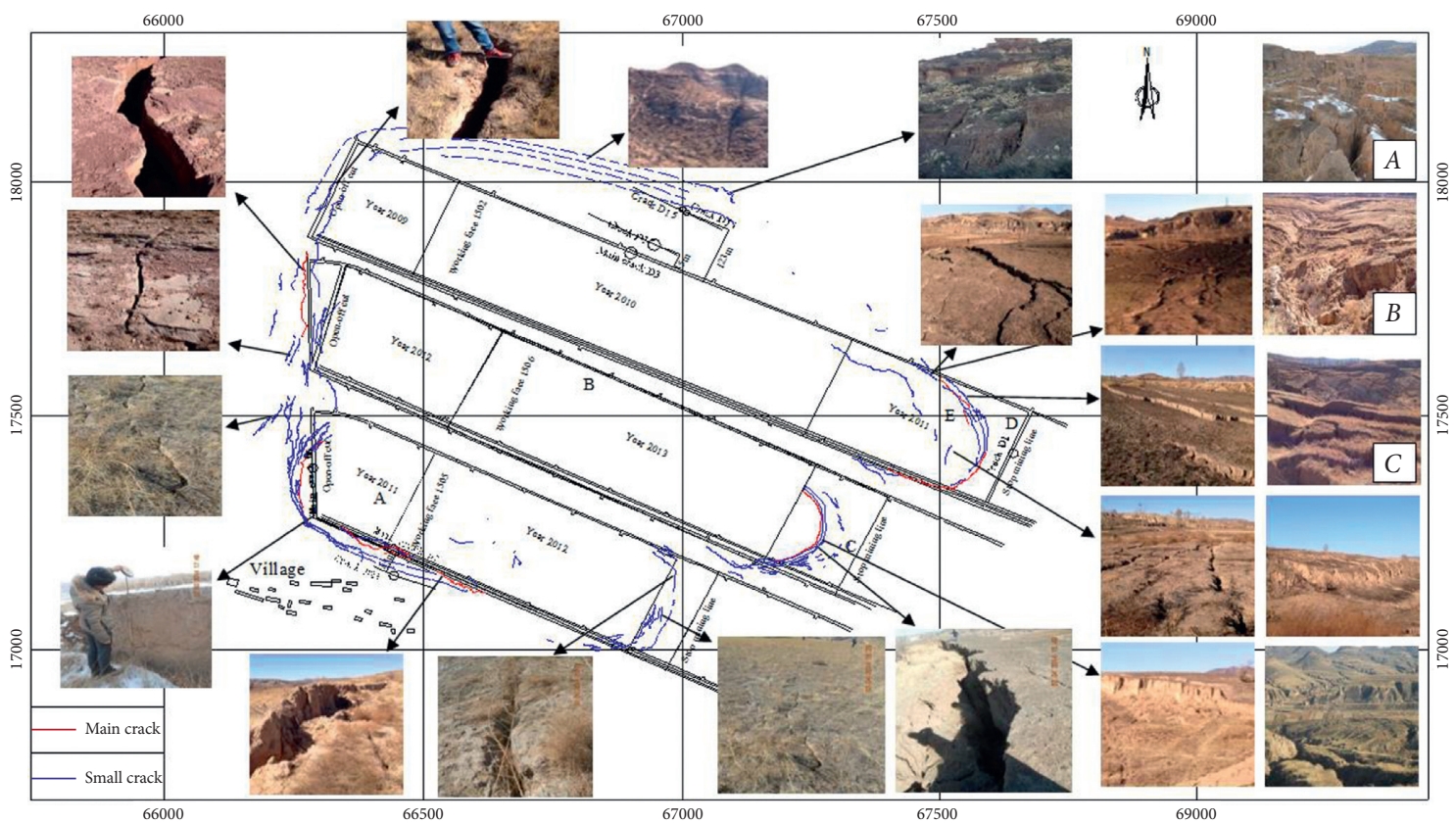

Figure 3: Distribution of surface cracks and cracks relative position and cracks photos. 


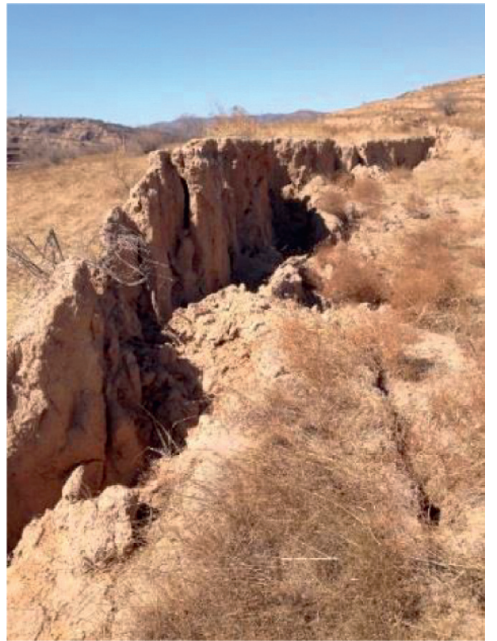

(a)

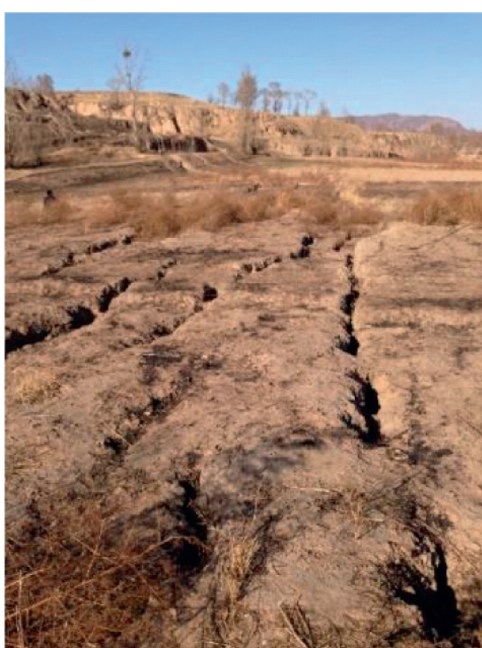

(b)

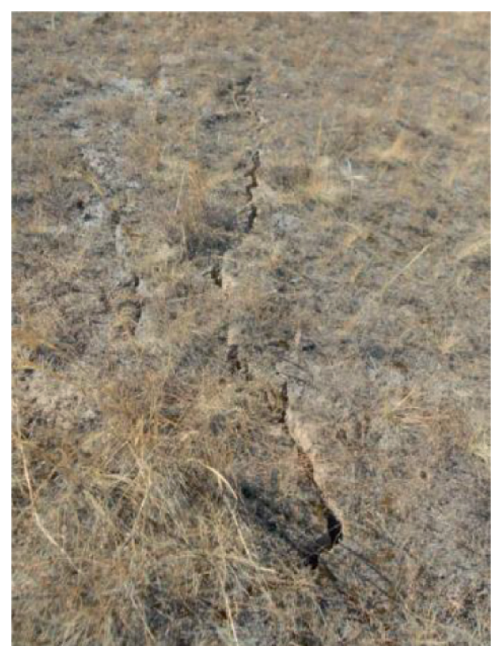

(c)

FIGURE 4: Morphology of surface cracks in loess-covered area. (a) Surface cracks near the boundary of goaf (main crack). (b) Crack right above the middle of goaf. (c) Crack near the surface movement basin margin.

2.2.2. Distribution Law of Surface Cracks in Bedrock Exposed Area. In 1502 working face, the main crack appears in the upward direction of the open-off cut near the mountain (Figure 5). The main crack is located in the bedrock exposed area. Compared with the main crack in the loess area, the width and drop of cracks are small. At the same time, the length of other cracks is shorter than that in the loess area. The uphill direction of working face 1502 is the mountain. There is no main crack in the mountain, but many parallel cracks with the same scale and uniform distribution are formed. In working face 1502, the terrain of the stoppage line is gentle, and many medium cracks are evenly distributed. With the generation of large cracks, there are few small cracks.

\section{Research Method}

3.1. Experimental Model Making. This simulation is limited by the size of the model frame, only working faces 1505 and 1506 are simulated. The comprehensive histogram of the mining area is shown in Figure 6. According to the actual geological and mining conditions of the mining area, a similar material model of the dip section of the coal face is established.

The size of the experimental frame model is $2990 \mathrm{~mm} \times 1610 \mathrm{~mm} \times 250 \mathrm{~mm}$, the geometric similarity constant of similar material model is 350 , the similarity constant of bulk density is 0.6 , the strength ratio is 210 , and the time ratio is 20 . The measuring points are evenly arranged on the surface of the model. The two sides of the observation points on the same floor are equally spaced by $5 \mathrm{~cm}$, and other points are spaced every $10 \mathrm{~cm}$ in the middle part. A total of six lines are arranged, from top to bottom as $A, B, C, D, E$, and $F$, as shown in Figure 7. Line $\mathrm{A}$ is the surface observation line, line $B$ is arranged on the interface between loose layer and bedrock, and lines $C, D, E$, and $F$ are placed on the bedrock of different layers.
3.2. Material Ratio. According to the similarity constant, the parameters of model laying are calculated. Quartz sand is selected as aggregate, and gypsum and lime mixture is used as cementation material. Combined with the bulk density and compressive strength of the simulation material, the material ratio and model making are carried out. Table 1 shows the geometric parameters and proportioning parameters of similar material model experiments.

3.3. Model Mining and Observation. After the completion of the model, first mining working face 1505, and then mining working face 1506, the subsidence is observed four times, two times before mining, and the average value was taken as the initial value, and once after the mining of working faces 1505 and 1506, respectively. The accuracy of the observed subsidence is higher than $\pm 0.2 \mathrm{~mm}$.

\section{Results and Discussion}

4.1. Distribution Laws of Mining Crack. After the mining, the upper roof collapsed and a large range of collapse occurred. The width of the caving zone was $540 \mathrm{~mm}$ and the height was $432 \mathrm{~mm}$. The height of the caving zone was about $5 \sim 6$ times the coal thickness. The height of the fracture zone is $220 \mathrm{~mm}$, and the bending zone reaches the ground surface. There are three kinds of mining affected zones in overlying strata, including caving zone, fracture zone, and bending zone, which is a typical "three-zone" model.

After the mining of working faces 1505 and 1506, cracks appear on the left and right sides of the goaf. On the left, a large crack appears just above the open-off cut of working face 1505 (such as crack 2 in Figures 8 and 9). With the passage of time, the crack gradually becomes larger and forms the main crack. The depth of the main crack runs through the whole loose layer and reaches the bedrock surface. The width of the main crack is consistent with the 


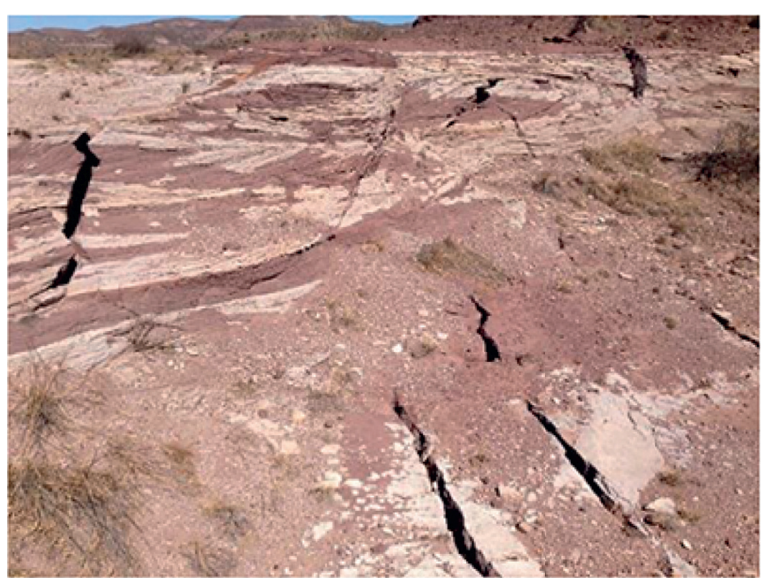

(a)

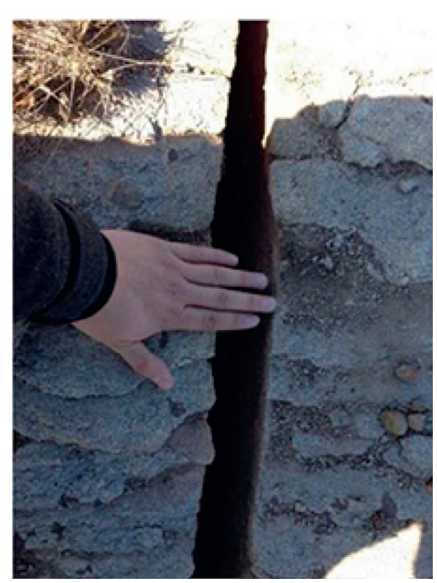

(b)

FIgURE 5: Morphology of surface cracks in bedrock exposed area.

measured situation and finally forms the step shape shown in crack 2 . At the side where the large crack is far away from the goaf, some small cracks (such as crack 1) are gradually produced, and the distance between the outermost crack of the goaf and the large crack is $328 \mathrm{~mm}$.

On the right, two cracks also appear on the side of the 1506 working face that deviates from the working face (such as crack 3 and crack 4). The main characteristics of the cracks on the right side of the goaf are that the distance between the outermost crack and the crack above the mining boundary is $231 \mathrm{~mm}$. With the gradual transfer of overburden movement to the surface, both sides of the surface main crack (crack 3 ) above the mining boundary of working face 1505 gradually subsided and moved, and the subsidence difference on both sides of the crack gradually increased and finally formed a bench crack with a drop of $1.5 \mathrm{~m}$. The maximum width of crack 3 is $2.1 \mathrm{~m}$, and the final depth of crack 3 is $140 \mathrm{~m}$. It is quite different from the general mining subsidence studies or the maximum depth of cracks measured in other areas (generally less than $10 \mathrm{~m}$ ). The main reason is that the lithology of overburden rock in the study area is hard and sudden subsidence occurs in the mining process, resulting in the surface deformation rate is large, thus forming cracks throughout the loose layer. There are cracks on both sides of the goaf, and the development morphology and geometric characteristics of the cracks are basically consistent.

Overall, the above mining face belongs to the typical three-zone mining mode. The main fractures are mainly distributed near the edge of the goaf, which is consistent with the O-ring fracture distribution theory.

\subsection{Reasons for the Difference of Crack Development in Dif- ferent Surface Coverage Areas. The distribution of surface fractures is consistent with the O-ring theory. According to the O-ring theory, after mining, the fractures are mainly distributed around the goaf, similar to the O-shape circle. However, in different geotechnical coverage areas, the de- velopment rules of surface cracks are different.}

(1) The cracks in the loess-covered area are fully developed, with various types and different laws. The reasons are as follows:

(a) In the loess-covered area, the loess structure is soft and has significant anisotropy. Due to the existence of loess, it is equivalent to softening the overlying layer.

(b) The mechanical strength of resistance to tensile deformation, resistance to compression deformation, and resistance to bending deformation is very low. In particular, the tensile deformation resistance is very weak. When the tensile deformation capacity of the ground surface exceeds $2-3 \mathrm{~mm} / \mathrm{m}$, the ground surface will be broken and cracks will appear. So, the surface cracks in the loess-covered area are fully developed, with both large and small cracks.

(c) At the same time, the vertical joints in the loess are fully developed, and vertical cracks are easily formed after being disturbed by mining. Due to the development of vertical joints in the loess and the soft shear resistance, large vertical cracks of the cutoff type are easily formed in the loess above the cracks in the bedrock surface; and around the large cracks, the loess has a very weak tensile deformation resistance. Therefore, many small irregular cracks are formed around the large crack.

(2) Compared to the loess-covered area, the cracks in the bedrock exposed area are relatively small but have strong regularity. The reasons are as follows:

(a) The bedrock in the bedrock exposed area is directly exposed on the ground surface without loose layer covering. Compared with the loesscovered area, the overlying rock is generally stronger in lithology, and the bedrock has stronger resistance to deformation. Therefore, the number of surface cracks in the bedrock exposed area is small, the width is small, and the depth is shallow. 


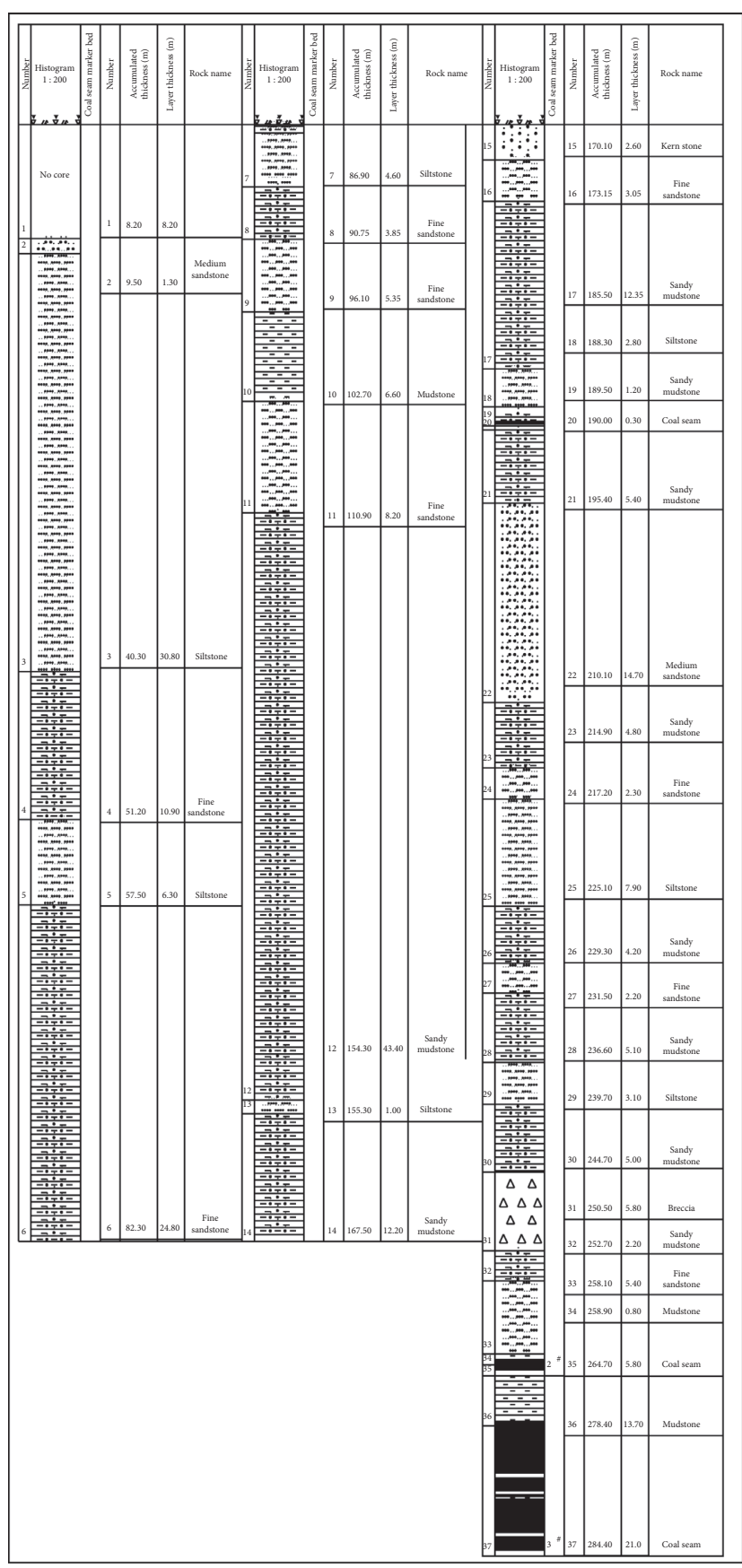

FIGURE 6: Comprehensive histogram of the borehole.

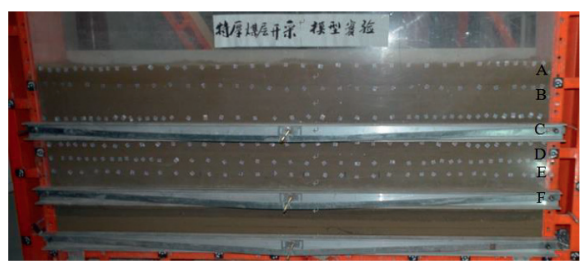

FigURE 7: Experimental model and measuring point layout. 
TABLE 1: Material ratio table of model test.

\begin{tabular}{|c|c|c|c|c|c|c|c|}
\hline & Rock stratum & Layer thickness (mm) & $\begin{array}{c}\text { Material ratio } \\
\text { Sand : lime: gypsum }\end{array}$ & Sand (kg) & Lime $(g)$ & Gypsum (g) & Water (ml) $7 \%$ calculation \\
\hline 1 & Loose layer & 150 & & & & & \\
\hline 2 & Sandy mudstone & 540 & $120: 4: 6$ & 536.3 & 17876.9 & 26815 & 40670 \\
\hline 3 & Fine sandstone & 105 & $40: 3: 2$ & 107.6 & 5377.8 & 8067 & 8470 \\
\hline 4 & Coal seam & 60 & $20: 3: 7$ & 19.5 & 1200.0 & 300 & 1470 \\
\hline 5 & Sandy mudstone & 250 & $120: 4: 6$ & 248.4 & 8280.0 & 12420 & 18837 \\
\hline
\end{tabular}

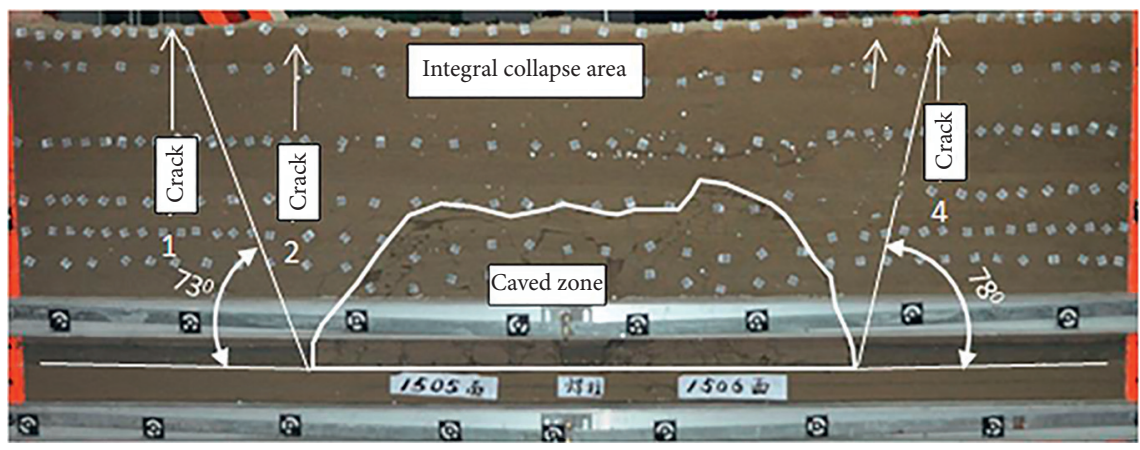

FIgURE 8: Crack distribution and overburden failure map of model mining.

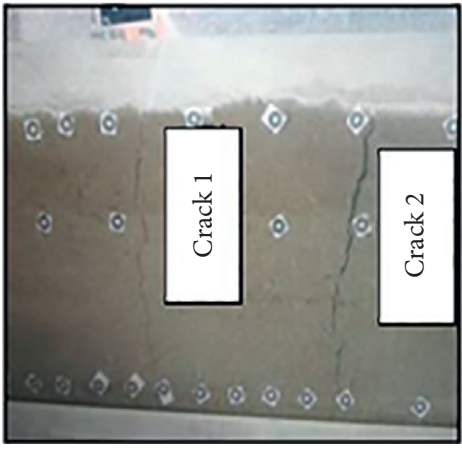

(a)

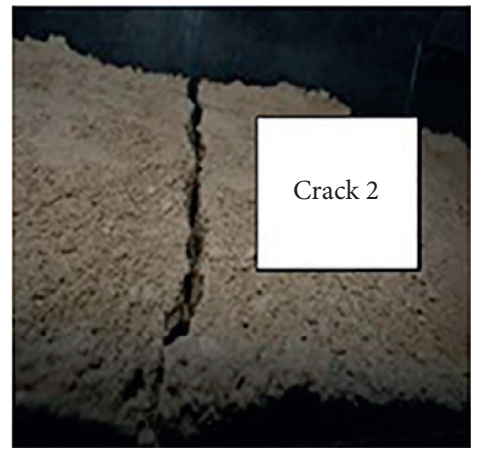

(b)

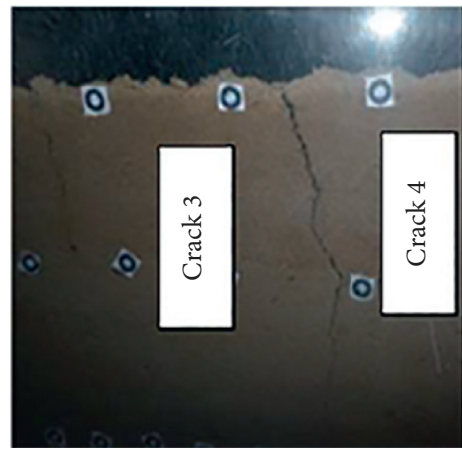

(c)

Figure 9: Local enlarged map of surface crack distribution.

(b) The generation of cracks in the bedrock mainly develops along the weak surface of the rock mass. Because the distribution of weak surfaces in the rock body has a strong regularity overall, the distribution of the cracks in the bedrock also has a strong regularity. After the cracks are exposed on the surface, they also have strong regularity; there are many cracks with the same scale and distributed evenly and in parallel.

\section{Conclusion}

Based on the analysis of the existing and measured data of the extrathick coal seam in the Datong mining area, combined with the similar material model test research, the following main conclusions are drawn.

(1) Three mining faces belong to the typical three-zone mining mode. The main fracture is consistent with the O-ring fracture distribution theory.
(2) In the loess-covered area, cracks are fully developed. The main cracks are mainly located above the openoff cut, outside of the open-off cut and the stoppage line side that is deviated from the working face. There are many secondary cracks around the main crack, with a large crack density and few cracks in the outer edge of the main crack.

(3) Compared with the loess-covered area, the width, length, number, and step drop of surface cracks in the bedrock exposed area are smaller. There is no main crack, and there are many cracks with the same scale and distributed evenly and in parallel.

\section{Data Availability}

The data used to support the findings of this study are available from the corresponding author upon request.

\section{Conflicts of Interest}

The authors declare no conflicts of interest. 


\section{Authors' Contributions}

W.Y. conceptualized the study. Y.Y. developed methodology. W.Y. provided the software. H.D. and J.G. performed validation. W.Y. performed formal analysis. Y.Y. performed investigation. Y.Y. provided the resources. J.G. performed data curation. Y.Y. wrote the original draft. W.Y. reviewed and edited the article. J.G. performed visualization. H.D. supervised the study. Y.Y. performed project administration. Y.Y. was responsible for funding acquisition. All authors have read and agreed to the published version of the manuscript.

\section{Acknowledgments}

This research was funded by the Fundamental Research Funds for the Central Universities"(2021YQDC09), National Natural Science Foundation of China (Grants nos. (50974122 and U1810203), the Youth Backbone Teacher Support Program of Henan Polytechnic University (Grants no. 2019XQG-07), the Fundamental Research Funds for the Universities of Henan Province (Grant no.NSFRF200314), the Henan Scientific and Technological Projection (Grant no.212102310012), the Open Fund of State Key Laboratory of Water Resource Protection and Utilization in Coal Mining (Grants nos.WPUKFJJ2019-20 and WPUKFJJ2019-17).

\section{References}

[1] T. A. Elmira, K. Reza, A. Mohammad, and R. T. Mohammad, "A review of studies on sustainable development in mining life cycle," Journal of Cleaner Production, vol. 229, pp. 213231, 2019.

[2] Anonymous, "Sustainable management of mining operations," Mining Engineering, vol. 61, no. 2, p. 22, 2009.

[3] C. Li, H. Xie, M. Gao, J. Xie, G. Deng, and Z. He, "Case study on the mining-induced stress evolution of an extra-thick coal seam under hard roof conditions," Energy Science \& Engineering, vol. 8, no. 9, pp. 3174-3185, 2020.

[4] B. Unver and N. E. Yasitli, "Modelling of strata movement with a special reference to caving mechanism in thick seam coal mining," International Journal of Coal Geology, vol. 66, no. 4, pp. 227-252, 2006.

[5] Y. H. Pang and G. F. Wang, "Top-coal caving structure and technology for increasing recovery rate at extra-thick hard coal seam," Journal of China Coal Society, vol. 42, pp. 817-824, 2017.

[6] J. Caron, S. Durand, and H. Asselin, "Principles and criteria of sustainable development for the mineral exploration industry," Journal of Cleaner Production, vol. 119, pp. 215-222, 2016.

[7] R. I. Maczkowiack, C. S. Smith, G. J. Slaughter, D. R. Mulligan, and D. C. Cameron, "Grazing as a post-mining land use: a conceptual model of the risk factors," Agricultural Systems, vol. 109, pp. 76-89, 2012.

[8] B. Xia, J. Jia, B. Yu, X. Zhang, and X. Li, "Coupling effects of coal pillars of thick coal seams in large-space stopes and hard stratum on mine pressure," International Journal of Mining Science and Technology, vol. 27, no. 6, pp. 965-972, 2017.
[9] J. Ju and J. Xu, "Structural characteristics of key strata and strata behaviour of a fully mechanized longwall face with $7.0 \mathrm{~m}$ height chocks," International Journal of Rock Mechanics and Mining Sciences, vol. 58, pp. 46-54, 2013.

[10] B. Yu, "Behaviors of overlying strata in extra-thick coal seams using top-coal caving method," Journal of Rock Mechanics and Geotechnical Engineering, vol. 8, no. 2, pp. 238-247, 2016.

[11] B. Yu, J. Zhao, T. Kuang, and X. Meng, "In situ investigations into overburden failures of a super-thick coal seam for longwall top coal caving," International Journal of Rock Mechanics and Mining Sciences, vol. 78, pp. 155-162, 2015.

[12] H. M. Li, D. J. Jiang, and D. Y. Li, "Analysis of ground pressure and roof movement in fully-mechanized top coal caving with large mining height in ultra-thick seam," Journal of China Coal Society, vol. 39, pp. 1956-1960, 2014.

[13] C. Gao, N. Z. Xu, and G. Liu, "Research on actual measurement of surface subsidence law for fully-mechanized top coal caving in extra thick seam," International Journal of Coal Science \& Technology, vol. 42, pp. 106-109, 2014.

[14] J. T. Guo, Y. G. Yan, and H. Y. Dai, "Determination of ground movement parameters under insufficient mining condition based on simulation results of FLAC3D," Journal of $\mathrm{Me}$ chanical Engineering Research, vol. 25, pp. 43-46, 2010.

[15] R. Gao, J. X. Yang, T. J. Kuang, and H. J. Liu, "Investigation on the ground pressure induced by hard roof fracturing at different layers during extra thick coal seam mining," Geofluids, vol. 2020, Article ID 8834235, 15 pages, 2020.

[16] R. Gao, B. J. Huo, H. C. Xia, and X. B. Meng, "Numerical simulation on fracturing behaviour of hard roofs at different levels during extra-thick coal seam mining," Royal Society Open Science, vol. 7, Article ID 191383, 2020.

[17] L. Ma, J. G. Zhang, and X. Chen, "Comprehensive evaluation of blast casting results based on unascertained measurement and intuitionistic fuzzy set," Shock and Vibration, vol. 2021, Article ID 8864618, 14 pages, 2021.

[18] L. Ma, J. Q. Zhao, and J. G. Zhang, "Slope stability anylsis based on leader dolphins herd algorithm and simplified bishop method," IEEE Access, vol. 9, p. 1, 2021.

[19] W.-B. Guo, H.-S. Wang, G.-W. Dong, L. Li, and Y.-G. Huang, "A case study of effective support working resistance and roof support technology in thick seam fully-mechanized face mining with hard roof conditions," Sustainability, vol. 9, no. 6, p. 935, 2017.

[20] Y. Lan, R. Gao, B. Yu, and X. Meng, "In situ studies on the characteristics of strata structures and behaviors in mining of a thick coal seam with hard roofs," Energies, vol. 11, no. 9, Article ID 2470, 2018.

[21] Y. Chen, S. Ma, and Y. Yu, "Stability control of underground roadways subjected to stresses caused by extraction of a $10-\mathrm{m}$ thick coal seam: a case study," Rock Mechanics and Rock Engineering, vol. 50, no. 9, pp. 2511-2520, 2017.

[22] R. Singh, P. K. Mandal, A. K. Singh, R. Kumar, J. Maiti, and A. K. Ghosh, "Upshot of strata movement during underground mining of a thick coal seam below hilly terrain," International Journal of Rock Mechanics and Mining Sciences, vol. 45, no. 1, pp. 29-46, 2008.

[23] C. Huang, Q. Li, and S. Tian, "Research on prediction of residual deformation in goaf of steeply inclined extra-thick coal seam," PLoS One, vol. 15, Article ID e0240428, 2020.

[24] J. Wang and Z. Wang, "Systematic principles of surrounding rock control in longwall mining within thick coal seams," International Journal of Mining Science and Technology, vol. 29, no. 1, pp. 65-71, 2019. 
[25] L. Nayzar, S. Takashi, S. Hideki, H. Akihiro, and M. Kikuo, "Numerical analysis of interaction effects in double extrathick coal seams mining," Procedia Earth and Planetary Science, vol. 6, pp. 343-349, 2013.

[26] K. Matsui, H. Shimada, and T. Sasaoka, "Some consideration in underground mining systems for extra thick coal seam," Coal International, vol. 2, pp. 38-41, 2011. 